\title{
UAV STRATEGIES VALIDATION AND REMOTE SENSING DATA FOR DAMAGE ASSESSMENT IN POST-DISASTER SCENARIOS
}

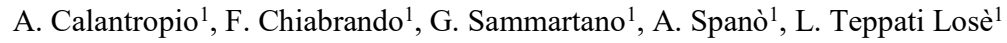 \\ ${ }^{1}$ DAD - Dipartimento di Architettura e Design, Politecnico di Torino, Viale Mattioli 39, 10129 Torino, Italia. \\ (alessio.calantropio; filiberto.chiabrando; giulia.sammartano; antonia.spano; lorenzo.teppati) @polito.it
}

\author{
Commission III, ICWG III/IVa; Commission I, ICWG I/II
}

KEY WORDS: UAV photogrammetry, Rapid Mapping, Remote Sensing, Seismic emergency, 3D models, Damage assessment

\begin{abstract}
:
The recent seismic swarms, occurred in Italy since August 2016, outlined the importance of deepen Geomatics researches for the validation of new strategies aimed at rapid-mapping and documenting differently accessible and complex environments, as in urban contexts and damaged built heritage. In the emergency response, the crucial exploitation of technological advances should obtain and efficiently organize high-scale reliable geospatial data for the early warning, impact, and recovery phases. Fulfilling these issues, among others, the Copernicus EMS, has played by now an important role in immediate and extensive damage reconnaissance, as in the case of Centre Italy. Nevertheless, the use of remote sensing data is still affected by a problem of point-of-view, scale and detectable detail. Nadir images, airborne or satellite, in fact, strongly limited the confidence level of these products. The subjectivity of the operator involvement is still an open issue, both in the first fieldwork assessment, and in the following operational approach of interpretative damage detection and rapid mapping production. To overcome these limits, the introduction of UAV platforms for photogrammetric purposes, has proven to be a sustainable approach in terms of time savings, operators' safety, reliability and accuracy of results: the nadir and oblique integration can provide large multiscale models, with the fundamental information related to the façades conditions. The presented research, conducted within the Central Italy earthquakes events, will focus on potentialities and limits of UAV photogrammetry in the two documented sites: Pescara del Tronto and Accumoli. Here, the aim is not limited to describe a series of strategies for georeferencing, blocks orientation and multitemporal co-registration solutions, but also to validate the implemented pipelines as a workflow that could be integrated in the operative intervention for emergency response in early impact activities. Thus, it would be possible to use this 3D metric products as a reference-data for significative improvements of reliability in typical visual inspection and mapping, flanking the traditional nadir airborne- or satellite-based products. The UAV acquisitions performed in two damaged villages are displayed, in order to underline the implication of the spatial information embedded in DSM reconstruction and 3D models, supporting more reliable damage assessments.
\end{abstract}

\section{INTRODUCTION}

The recent lines of research within the Geomatics applied techniques in Disaster Management (DM) are going to pursue many targeted solutions in emergency response within the early warning, the early impact and the early recovery phases: search and rescue, damage monitoring, analysis and assessment, and emergency managements. The deployed methods try to enhance the balancing between rapidity, resources and accuracy of geospatial products. In fact, the operational post-disaster damage mapping is generally defined, as a set of endorsed procedures such as data processing of remote sensing data (optical images, SAR or LiDAR) (https://www.disasterscharter.org) for cartographic production "dedicated to providing situational awareness emergency management and immediate crisis information for response, by means of extraction of reference (pre-event) and crisis (post-event) geographic information/data" (Emergency Mapping Guidelines/IWG-SEM, 2015). Specifically, the mapping approaches for Building Damage Assessment (BDA) operations, are increasingly focusing toward new sensors applicability and 3D data validation in supporting the emergency mapping, flanking the traditional approaches based on remote sensing data. These procedures are usually focused on established approaches that are mainly referring to a visual interpretation of spatial data with a manual work of operators in BDA. In this framework the role of remote sensing has surely been well-established and deeply investigated: the use of LiDAR data (He et al., 2016), satellites (Bitelli, Camassi, Gusella, \& Mognol, 2004; Boccardo \& Giulio Tonolo, 2015) and aerial images too (Nex, Rupnik, Toschi, \& Remondino, 2014). These are time-consuming operations and sometimes they can be temporally segmented or imprecise, due to their nature and their intrinsic scale, no longer satisfying the requirements of detail and readable information, especially in dense historical urban centres (Kerle, 2010; Lemoine,
Corbane, Louvrier, \& Kauffmann, 2013; Rastiveis, Samadzadegan, \& Reinartz, 2013; Voigt et al., 2011).

The aims of the ongoing methodological refinements in the providing high-scale geospatial data, could be dedicated, on one hand, to the maximization of information extraction in imageand range-based acquisitions, as well as the management in all the phases of an emergency response, and, on the other hand, to sustain the operative fieldwork in the damaged context, in order to support the direct analysis and damage assessment, reducing the operator permanence and exposure to the danger occurrences. In terms of acquisition strategies, the use of UAV platforms is nowadays a powerful solution for photogrammetric purposes, employed for image acquisition and high-scale reconstruction of accurate 3D surface models, compared to those ones that usually are derived by consolidated remote-sensing imaging methods.

For these reasons, the new era of BDA procedures is concerning the possibility of using both nadir and oblique images allowing to automatically or semi-automatically extract useful information, not only related to the roofing condition but also, and above all, to the masonries condition and considerable cracks pattern of the façades. Moreover, the joined use of orthoimages and Digital Surface Models (DSM) can support the operative rapid mapping inspections with precision, in relation to the whole 3D development of the building (roofing and façades), supporting a more reliable damage assessment. In these direction, some of the recent researches are conducted to the processing of multi perspective airborne and UAV image data, with automatic analysis for data extraction, mainly devoted to automatic pixel and object-based approaches (Crommelinck et al., 2016), and helped by deep learning methods, i.e. automatic recognition of the images patch of damaged areas (Cusicanqui, Kerle, \& Nex, 2018; Fernandez Galarreta, Kerle, \& Gerke, 2015; Vetrivel, Gerke, Kerle, Nex, \& Vosselman, 2017). 


\section{IMAGING APPROACHES SUPPORTING DISASTER MANAGEMENT (DM)}

\subsection{Satellite and airborne aerial images}

The Copernicus Emergency Management Service (EMS) is one of the six services offered by the Copernicus Programme, the largest Earth observation programme which aims to develop an European information service based on satellite and in situ data. This service is currently used to provide information for supporting the DM operations: the European Forest Fire Information System (EFFIS) and Global Wildfire Information System (GWIS), the European Flood Awareness System and the Copernicus EMS - Mapping. Starting from the beginning of the service activities, the $1^{\text {st }}$ of April 2012 (http://emergency. copernicus.eu), only the use of Remote Sensing (RS) or/and aerial data is considered as a primary source for Rapid Mapping operations. This aspect is connected to several factors: RS data, according to the platforms typical characteristics, allow to acquire information in large areas with limited or no accessibility, and easily to obtain geographic information with a good Level of Detail (LOD) at an urban scale.

The Civil Protection, among others involved in the emergency response, usually activates the Emergency Management Service. The information that are typically needed after a natural hazard, as soon as possible, are usually the location and extent of the event, the intensity of the damage connected to infrastructures and buildings and an evaluation of the number of affected people. As it is possible to deduce, the maps of the area are the first important documents for organizing the activities in the area during and after the search and rescue phase.

The workflow of the service, considering only the post event map production, is the following (Ajmar, Boccardo, Disabato, \& Giulio Tonolo, 2015): RS/Aerial acquisition; Data processing: Image pre-processing (geocoding, orthorectification, coregistration); extraction of Post-event information; extraction of value-added information; Post-event emergency information covering affected area; Map Dissemination.

Once the service is activated, three different products as is reported in (Boccardo, 2013) could be obtained: reference maps, delineation maps and grading maps (Figure 1 provide an assessment of the damage grade and of its evolution if requested. In this specific paper the focus will be oriented to the produced grading maps in the area of central Italy that are available, according to the EMS rapid mapping procedure, in a time range between 3 and $12 \mathrm{~h}$.

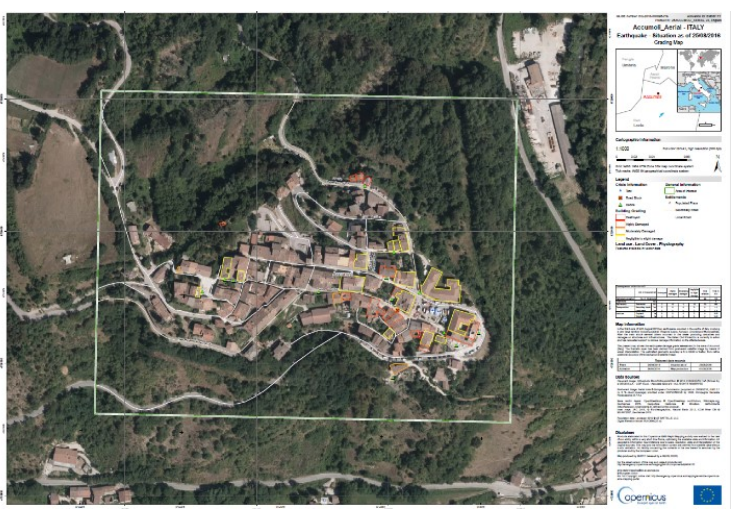

Figure 1. Post-event Grading Map for Accumoli (RI), Italy.

Aerial image from (C) European Commission (acquired on

25/08/2016, GSD $0.1 \mathrm{~m}, 0 \%$ cloud coverage) provided under COPERNICUS by CGR, Compagnia Generale Riprese aeree.

However, satellite images have strong limitations due to the fact that the images are captured directly with a limited off-nadir angle sensor configuration; in doing so, damages occurred to the roofs are easily detectable, whereas damages to the façade are evaluated according to the debris located in their close proximity. To overcome these well-known limitations, a photogrammetric approach was adopted right after the Haiti Earthquake in 2010, where airborne oblique multi-perspective Pictometry data were processed in a two-step approach (Lemoine et al., 2013; Voigt et al., 2011). Theoretically, starting from the currently employed aerial camera, is certainly possible to extract, in addition to the traditional orthoimages, further data, like Digital Surface Models (DSM) or 3D features. Nowadays, unfortunately, the effective chance to obtain complex 3D model and information's visualization from those data are not yet implemented in the EMS service. As general remarks, a preliminary analysis of the main pros and cons of RS approach are reported in the next Table 1:

\begin{tabular}{c|c|}
\hline Pros & Cons \\
\hline $\begin{array}{c}\text { Fast data acquisition of areas } \\
\text { with limited, uneasy or } \\
\text { impossible access. }\end{array}$ & $\begin{array}{c}\text { Accuracy of the results are } \\
\text { correlated with the phenomena } \\
\text { observed. }\end{array}$ \\
\hline $\begin{array}{c}\text { Monitoring areas for observing } \\
\text { changes over time. }\end{array}$ & $\begin{array}{c}\text { Acquisition of data only during } \\
\text { daylight/good weather } \\
\text { conditions (optical satellites). }\end{array}$ \\
\hline $\begin{array}{c}\text { Fast assessment of dense urban } \\
\text { areas, large rural territories and } \\
\text { linear infrastructures. }\end{array}$ & $\begin{array}{c}\text { Image resolution compared with } \\
\text { UAV based methodologies }\end{array}$ \\
\hline \multicolumn{2}{|c|}{ Table 1. Pros and Cons of RS products related to the emergency mapping }
\end{tabular}

According to the afore mentioned consideration is clearly known the importance of the 3D information component, today easily gatherable from oblique images. This aspect suggests the need of introducing easy to deploy and easy to use platform as UAVs (Unmanned Aerial Vehicles), that have already demonstrated their effectiveness in other situations where a fast and accurate reconnaissance of relatively large area was required. The issues connected to the UAV will be discussed in the next section since this new approach for imaging the different disaster scenario is closely becoming a standard for mapping purpose especially for early impact applications.

\subsection{Deploying Unmanned Aerial Vehicles (UAV) mapping} Nowadays certainly the use of UAV photogrammetry need to be consider a complementary or sometimes a new technology able to image the area affected by the natural hazard that could be replace the traditional EMS data acquisition systems. In fact, more recently UAVs are being tested and even more employed in in Early Impact Mapping contexts, both in demonstration exercises (Boccardo, Chiabrando, Dutto, Tonolo, \& Lingua, 2015; Rester, Spruyt, De Groeve, Damme, \& Ali, 2013) or in a real scenario (Duarte, Nex, Kerle, \& Vosselman, 2017; Ezequiel et al., 2014).

Using imagery data acquired from UAV platforms could potentially overcome the above-mentioned issues, thanks to the ease of deployment and the higher resolution of the raw data. In this context a test on using airborne images, as a halfway technique to test the potential of acquiring data below the cloud line, without so being affected of bad weather conditions. This line of research is reported as well in this interesting article published in the web page of the Copernicus EMS service (http://emergency.copernicus.eu/mapping/ems/ how-copernicusemergency-management-service-supported-responses-majorearthquakes-central-italy). The feature underlines the importance of UAV integration "pilot study is currently underway for the Copernicus Emergency Management Service, investigating the potential of deploying manned and unmanned aerial systems (UAS) for acquiring imagery in support of emergency management actors" that will be supported by the achieved tests in the next sections. As already stated in the introduction, emergency events affecting historical urban centres and widespread built heritage, often densely inhabited and serried 
built, need great efforts by Geomatics techniques applied to the metric documentation in order to tailor advanced methods to the specific urban morphology of those crowdy contexts. Rapidity in acquisition times and low-cost sensors are challenging marks of the research toward documentation techniques, and they could be taken into consideration weighting post-processing times, as the best possible compromise between timeliness and accuracy. In particular, the constant growth in the use of UAVs has created new possibilities for rapid mapping purposes.

Furthermore, the integration of nadir and oblique images, nowadays easily acquired by UAV, has a key role in the high-scale spatial modelling. The metric content in the geometry and radiometry entirety is one of the main factors that lead to the improvement of the 3D models achievable with this technique. As a consequence, it is possible to state that the use of UAVs, alone or in a consolidated integration with other techniques, can improve and support different activities connected to a post-disaster scenario:

- First aid intervention and assistance for planning accessibility/practicability of spaces;

- Prompt Building Damage Assessment (BDA);

- Preliminary evaluation on securing equipment supplies, people and related budget.

Finally, in a second step, after the first emergency operation connected to search and rescue and building and infrastructure security, the use of this system could be useful also for a constant support to conservation and monitoring of the affected area i.e.:

- Multi-temporal structural building monitoring, for evaluation and prevention of potential collapse mechanisms

- Planning of focused intervention reasoned with technical expertise (structural and geotechnical engineers, restorers, construction managers and directors of conservation)

\section{THE CENTRE ITALY EARTHQUAKE: UAV-BASED DOCUMENTATION VALIDATION}

During the 2016 six large earthquakes occurred in the Central Italy Apennine Mountains: the two main events are the earthquake of Amatrice and Norcia. Specifically, the events are dated on 2016 August 24, 26, and October 26, 30; the moment magnitudes (M) of these events were $6.1,5.3,4.8,5.4,5.9$, and 6.5 , respectively. A few hours after the first earthquake, the Italian Civil Protection Departiment, DPC (Dipartimento della Protezione Civile) requested the activation of the Copernicus EMS, which came into operation later in the morning of the $24^{\text {th }}$ August.

Other than the satellite images, were also activated airborne survey operations on the most affected cities for a better integration of data already provided by the satellite source; the aerial operations took place in the afternoon of the $25^{\text {th }}$ August, due to previous inadequate weather conditions for an earlier deployment. The use of the mapping module during the earthquake in Central Italy gave the possibility to the authorities to recognize the damaged areas and lead to the production of a total of 120 maps for assisting the disaster response activities; a total of 13 reference and grading maps were drawn, with a total coverage of about $320 \mathrm{~km}^{2}$. The satellite data obtained from the EMS - Mapping of Copernicus were acquired using satellite images from WorldView-2 (0,5 m GSD) and Deimos-2 (1 m GSD). The aerial data were acquired with a GSD of $10 \mathrm{~cm}$.

Starting from early September 2016 up to the end of December 2016, the task force of the Politecnico di Torino in cooperation with the RPAS (Remotely Piloted Aircraft Systems) group of the Italian Firefighters have been involved in different reconnaissance and survey activities in the areas affected by the seismic swarms. During the September and December missions, the group activities have been improved with the important contribution of the Geotechnical Extreme Events Reconnaissance Association (GEER) that organized and mobilized a team of U.S. and Italian multi-disciplinary researchers, to observe and document the effects of the 2016 Central Italy earthquakes (GEER 2016b, 2017a). From a Geomatics point of view the main objective of the on the field operations was connected to the documentation of the area using different acquisition systems like UAV and close-range photogrammetry, LiDAR (Light Detection And Ranging) and SLAM (Simultaneous Location and Mapping)-based mapping in order to produce $3 \mathrm{D}$ models and traditional 2D, 2.5D maps for evaluate and monitor the damage evolution. The survey operations have been performed along the seismic areas in different villages such us Accumoli (Figure 2), Pescara del Tronto (Figure 3), Amatrice, Castelluccio, Visso etc...

In addition to the traditional operations, different tests have been achieved for improving the typical employed workflows, in order to refine the capability of the different actors involved in the emergency operation after an earthquake or more in general after a natural hazard. In the next sections the obtained results in the areas of Accumoli and Pescara del Tronto are reported (Par.3).

\subsection{The acquisition campaigns}

As reported, several field campaigns (jointly conducted by VVFF, GEER and PoliTo) have been performed in the areas of Central Italy that have been affected by the seismic swarm. In this contribute the data collected in Accumoli and Pescara del Tronto will be analysed and commented: two missions were completed in Accumoli (in September and December) and four in Pescara del Tronto (August, September, October and December). Among the different sensors employed the focus will be on three different UAVs platforms that were tested: a fixedwing by Sensfly and two multi-rotors produced by DJI. A brief description of these three platforms is reported below:

- The fixed-wing eBee is a small and light device intended for the mapping of large area in short amount of time and was equipped with a digital camera Canon Power Shot S110 ${ }^{\mathrm{TM}}$, which offers a 1/1.7" Canon CMOS sensor, 12MP images, and a focal length of $5.2 \mathrm{~mm}$.

- The Phantom 4 is a small and quite portable quadcopter (weight of around $1.4 \mathrm{~kg}$ ) and is equipped by a custom $4 \mathrm{~K}$ video camera that has a 1/2.3" CMOS sensor, 94-degree field of view, 12.4 MP images, and a focal length of infinity.

- $\quad$ The Inspire 1 is again a quadrotor but is bigger than the Phantom 4 (around $3 \mathrm{~kg}$ ) and was equipped with a ZENMUSE X5 camera, CMOS Sensor focal length $15 \mathrm{~mm} F / 1.7-\mathrm{F} / 16$, field of view $72^{\circ}$ for $4 \mathrm{~K}$ video and images $16 \mathrm{MP}(4608 \times 3456)$.

\subsubsection{The Accumoli site}

\begin{tabular}{|l|l|l|}
\hline & SEPTEMBER & DECEMBER \\
\hline $\mathrm{T}$ acquisition & 10 minutes & 10 minutes \\
\hline $\mathrm{T}$ processing & Ca 5 hours & $\mathrm{Ca} 6$ hours \\
\hline $\mathrm{N}^{\circ}$ images & 250 & 240 \\
\hline Flight heigh & 130 & 110 \\
\hline Tie points & 1.983 .428 & 921.838 \\
\hline Dense Cloud & 139.798 .253 & 69.467 .671 \\
\hline GSD (m/pix) & 0.05 & 0.04 \\
\hline Mean RMSe GCPs $(\mathrm{m})$ & 0.052 & 0.036 \\
\hline Mean RMSe CPs $(\mathrm{m})$ & 0.038 & 0.045 \\
\hline
\end{tabular}

Table 2. Accumoli datasets of September and December

In the site of Accumoli a standard approach was adopted in the field campaign: firstly, a set of targets was placed on the field and then measured with RTK (Real Time Kinematic) GNSS techniques, reaching an overall accuracy of 3-5 centimetres, that was considered acceptable for that emergency contexts. Thereafter, the UAV acquisition planning, with a nadiral configuration of cameras, has been performed at different flight altitudes and then integrated with another oblique configuration too. The main details of the two campaigns in Accumoli are 
reported in the following Table 2; some examples of the processed products are shown in Figure 2.

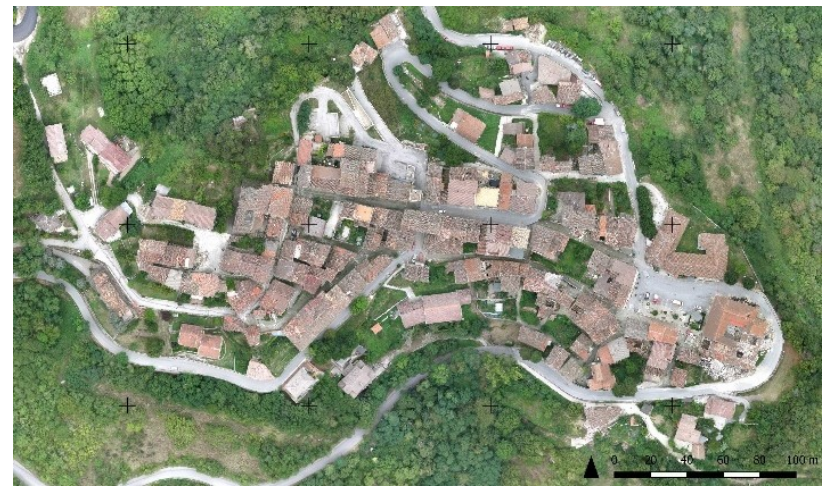

(a)

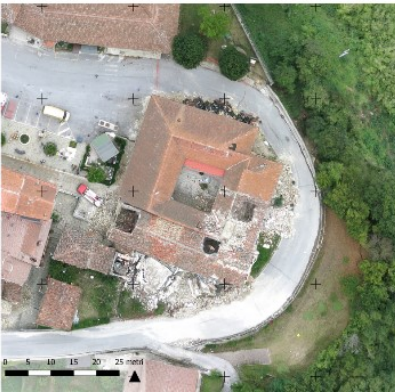

(b)

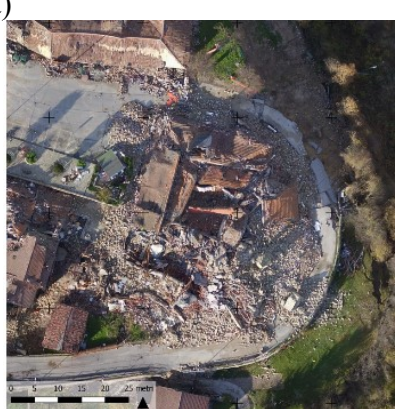

(c)
Figure 2. Digital orthoimage by UAV in Accumoli, flight height $130 \mathrm{~m}$ (September 2016), GSD $=5 \mathrm{~cm} / \mathrm{px}$. Comparison between T1-T4 in the eastern area of Accumoli: zoomed excerpt of T2, September (b) and T4, December (c).

\subsubsection{The Pescara del Tronto site}

\begin{tabular}{|l|c|c|c|c|}
\hline & AUGUST & SEPTEMBER & OCTOBER & DECEMBER \\
\hline Tacquisition & $11 \mathrm{~min}$ & $10 \mathrm{~min}$ & $30 \mathrm{~min}$ & $\begin{array}{c}18 \\
\text { minutes }\end{array}$ \\
\hline $\mathrm{T}_{\text {processing }}$ & $\sim 6 \mathrm{~h}$ & $\sim 6 \mathrm{~h}$ & $\sim 9 \mathrm{~h}$ & $\sim 6 \mathrm{~h}$ \\
\hline $\mathrm{N}^{\circ}$ images & 137 & 124 & 345 & 400 \\
\hline Flight heigh & 150 & 110 & 145 & 100 \\
\hline Tie points & 1.074 .753 & 1.490 .075 & 1.150 .150 & 749.484 \\
\hline Dense Cloud & 56.382 .856 & 40.998 .577 & 57.912 .776 & 41.114 .451 \\
\hline GSD (m/pix) & 0.064 & 0.057 & 0.073 & 0.030 \\
\hline $\begin{array}{l}\text { Mean RMSE } \\
\text { GCPs (m) }\end{array}$ & 0.06 & 0.05 & 0.059 & 0.020 \\
\hline $\begin{array}{l}\text { Mean RMSE } \\
\text { CPs (m) }\end{array}$ & 0.051 & 0.06 & 0.061 & 0.026 \\
\hline
\end{tabular}

Table 3. Pescara del Tronto multi-temporal datasets

In the site of Pescara del Tronto the UAVs approach was tested and analysed more in deep (Par.3), especially since the area suffered huge and repeated damages for each of the different seismic events occurred.

In this case, multi-scale flights configurations were performed, and the use of oblique images was stressed in a more systematic way, in order to adopt a multi-temporal approach in the study of the site as well. Moreover, the impact of georeferencing strategies and images blocks orientation will be analysed, with number and distribution of GCPs (Ground Control Points), with the influence of the strips configuration, with the managements of multitemporal datasets. In the Table 3 and Figure 3 the main details of the campaigns conducted in Pescara del Tronto and some example of the achievable products are reported.

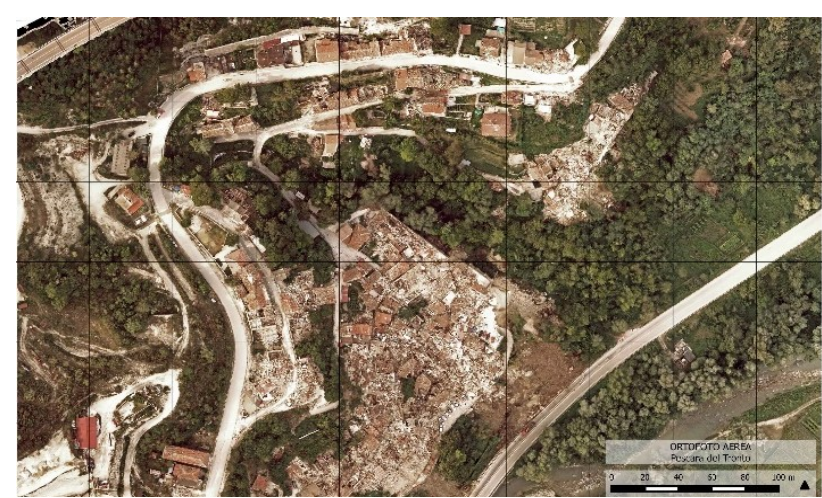

(a)

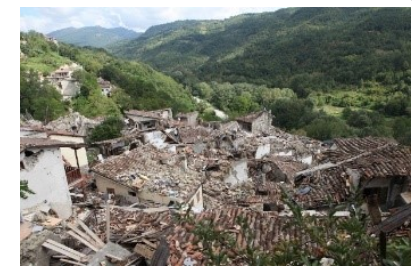

(b)

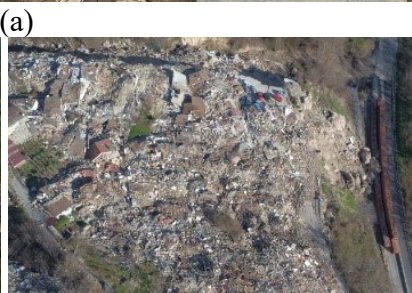

(c)
Figure 3. Digital orthoimage by UAV in Pescara del Tronto, flight height $110 \mathrm{~m}$ (T2, September 2016), GSD $=5 \mathrm{~cm} / \mathrm{px}$. Images from the Pescara del Tronto perched village after the August seismic shock, in the September first PoliTo recognition (b) and after the T3, October event, in the T4, December mission (c).

\subsection{The proposed validation}

The research experience presented in this contribution aims not only to describe the operative approach, implemented in the site of Pescara del Tronto and Accumoli: it will be validated as a sample of effective workflows that could be achieved using this kind of data in the early impact activities and emergency response. It would be also possible to use the obtained 3D metric products as a baseline-data for improvements in typical damage mapping pipelines. In this sense, more in deep, in the next sections, two steps of validation are thus proposed:

Validation on the 3D model and operative processing (Par.4)

Validation on its reliability, i.e. the gatherable 3D information for DM purposes (Par.5).

For the first one, the production of rapid and accurate geospatial products by UAV photogrammetric method is tested in the two sites of Accumoli and Pescara del Tronto after the central Italy earthquake. A simplified workflow is proposed according to different suggested strategies for georeferencing, blocks orientation and multitemporal co-registration solutions.

Besides, in the same Central Italy earthquake scenario, Copernicus provided the detection of the most damaged buildings for an early census of the non-safe buildings, based on a visual inspection for assessing the entity of the damages occurred, according to the European Macroseismic Scale (EMS-98). In the following study the authors propose an integration to the airborne data, supported with the 3D information provided by UAV acquisitions performed in two affected villages.

\section{OPERATIVE UAV APPROACH: suggested workflows}

Considering the threats of danger and the lack of resources (time, budget, operators) that is often encountered facing disastrous natural events, the in-situ deployment operation is one of the most complex and time-consuming operations: consequently, is the one with the larger time-exposure to danger for the operators' safety. The maximization of the informative content of UAV photogrammetric 3D models can be thus pursued by the application of effective of acquisition and processing strategies, to be applied in such cases of complex environments: 
- georeferencing measurements on fieldwork (Par.4.1), geometry of block acquisition configuration (Par.4.2), multi-temporal co-registration method (Par.4.3)

\subsection{Georeferencing strategies}

In the block orientation and georeferencing procedures, the measurement of control points plays a crucial role in the time balancing as well as in the confidence level of final metric results. The use of GPS/GNSS geodetic receiver in RTK mode, Figure 4(a), is a consolidated topographic approach for measuring GCPs on the terrain to georeference, compute Bundle Block Adjustment (BBA) and verify accuracy of photogrammetric reconstruction. Here is considered as the ground-truth for the parallel evaluation of useful alternative approaches, that can offer a good compromise in terms of reliability of the acquired data, time of the survey operations and economic cost of the instrument itself, as well.

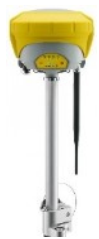

(a)

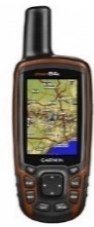

(b)

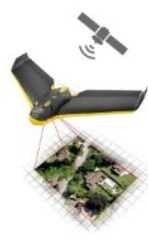

(c)
Figure 4. Tested strategies for georeferencing the UAV photogrammetric blocks. (a) GNSS RTK Geomax Zenith35 receiver, $\sim 10.000 €$; (b) Garmin GPSMAP ${ }^{\circ} 64 \mathrm{~s}$ handheld receiver, 300€; (c)

exterior orientation associated to the UAV images by GeoTag.

The use of consumer grade GPS/GNSS handheld receiver, Figure 4(b), has proved to be faster than the traditional RTK procedure, involving undoubtedly cheaper and easy-to-use instruments; however, this won't firstly overcome the related safety issues, as the operator will have to traverse dangerous areas anyway. The comparison of residual errors on check points (CPs), in Table 4, has been performed on the cartographic product, separately computed by use of GCPs measured by the two GNSS receivers, the geodetic RTK and the handheld receiver. The results demonstrated the expected problem of accuracy, in meters magnitude, affecting those types of receivers.

\begin{tabular}{|l|c|c|c|c|}
\hline \multirow{2}{*}{ handheld receiver } & \multicolumn{4}{|c|}{$\mathrm{n}^{\circ} 10 \mathrm{CPs}$} \\
\cline { 2 - 5 } & $\mathrm{X}$ & $\mathrm{Y}$ & $\mathrm{Z}$ & error \\
\hline Mean $(\mathrm{m})$ & 2.264 & 1.488 & 9.608 & 4.453 \\
\hline RMSE $(\mathrm{m})$ & 2.646 & 1.941 & 4.155 & 2.914 \\
\hline
\end{tabular}

Table 4. Residual errors about the validation of the handheld receiver in comparison with GNSS RTK measurements.

The use of the positioning information embedded in the acquired UAV images as exterior orientation, Figure 4(c), can be another valuable solution in case of impossibility to directly measure GCPs on the ground. The UAV device used in this case is the $\mathrm{eBee}^{\mathrm{TM}}$ Basic version, equipped with consumer GPS on board receiver; neither the RTK version nor the recent PPK version have been tested. It can provide, by the so-called geotag, the exterior orientation, i.e. the direct georeferencing of image shooting position. The comparison of the parallel use of geodetic GNSS receiver and images geotag is performed and validated, as reported in Table 5, and show more limited errors results in comparison with those ones from Table 4.

\begin{tabular}{|l|c|c|c|c|}
\hline \multirow{2}{*}{ direct georeferencing } & \multicolumn{4}{|c|}{$\mathrm{n}^{\circ} 34$ CPs } \\
\cline { 2 - 5 } & $\mathrm{X}$ & $\mathrm{Y}$ & $\mathrm{Z}$ & error \\
\hline Mean $(\mathrm{m})$ & 1.124 & 1.173 & 3.148 & 1.815 \\
\hline RMSE $(\mathrm{m})$ & 0.086 & 0.121 & 0.398 & 0.202 \\
\hline
\end{tabular}

Table 5. Residual errors about the validation of the use of exterior orientation by images Geotag in comparison with RTK measurements

Nevertheless, both solutions, compared to the standard GNSS receiver, cannot be declared suitable for the computation of a photogrammetric product that responds to an architectural or urban scale details, neither in planimetry nor in elevation. They can demonstrate however their efficacy in the production of rapid mapping high-scale and 3D products for BDA visual interpretation procedures.

\subsection{UAV blocks orientation strategies}

In the above-mentioned framework of the tight control over the economy of time and resources consumption in emergency contexts, a poor accessibility to the spaces could lead to the extremely useful maximization of aerial data acquisition and try to limit the terrestrial practicability.

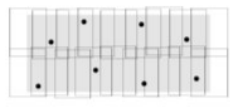

(I)

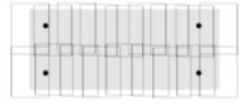

(II)

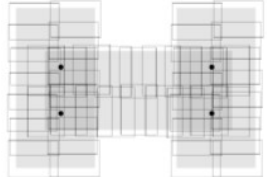

(III)
Figure 5. Images blocks configuration and GCPs arrangement: (I) single strip/dense GCPs; (II) single strip/limited GCPs; (III) integrated strips/limited GCPs.

Here is proposed an experimental analysis about the influence of images strips planning and GCPs distribution, as well as their combination (Figure 5), on the blocks orientation results, for an attempt of standardization in blocks acquisition geometry and GCPs planning. In the site of Pescara del Tronto village three types of solution (Figure 5) have been tested: blocks strips and GCPs distribution, as in Figure 6, are organized in order to reduce the number of ground measurements. The comparative results are reported in Table 6 and show the decisive contribution of the reinforcement in the geometric block configuration, despite the reduced number of GPSs.

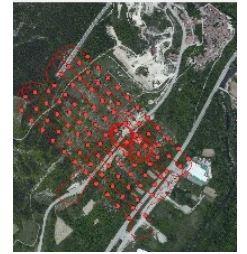

(a)

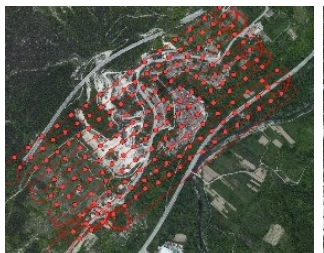

(b)

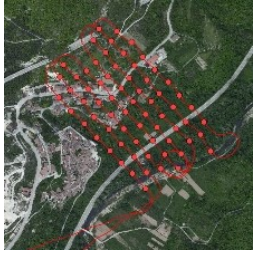

(c)
Figure 6. Images blocks acquired in Pescara del Tronto for the (III) configuration: (a) and (c) lateral strips; (b) central strip.

\begin{tabular}{|c|c|c|c|c|c|c|}
\hline \multicolumn{2}{|c|}{ Configuration } & \multicolumn{4}{c|}{ RMSE (m) } \\
\hline \multicolumn{2}{|c|}{} & $n^{\circ}$ & $X$ & $Y$ & $Z$ & error \\
\hline \multirow{2}{*}{ I } & GCPs & $\mathbf{1 8}$ & 0.018 & 0.016 & 0.019 & 0.018 \\
\cline { 2 - 7 } & CPs & 8 & 0.034 & 0.013 & 0.020 & 0.022 \\
\hline \multirow{2}{*}{ II } & GCPs & $\mathbf{4}$ & 0.006 & 0.0099 & 0.005 & 0.007 \\
\cline { 2 - 7 } & CPs & 22 & 0.026 & 0.017 & 0.028 & 0.024 \\
\hline \multirow{2}{*}{ III } & GCPs & $\mathbf{4}$ & 0.007 & 0.011 & 0.007 & 0.008 \\
\cline { 2 - 7 } & CPs & 22 & 0.026 & 0.018 & 0.018 & 0.020 \\
\hline
\end{tabular}

Table 6. Residual RMSE in the three blocks configuration, with different combination of GCPs.

\subsection{Multitemporal co-registration workflow}

The availability of multi-temporal datasets, in case of subsequent emergency events, brings the need to manage their spatial information and thus the possibility to implement a multiple photogrammetric blocks registration. A strategy of co-registration is proposed in the Figure 7 workflow and applied in the Pescara del Tronto datasets, as presented in (Par.2.1.2) and Table 3.

The methodological solution is based on the treatment of multiple times dataset, and on the use of a reference time (here T2) for the aerial triangulation computation. In this case, in the September's mission, it was possible to straightforwardly perform the topographic GNSS measurements procedures on fieldwork and the reliability of metric result was the most controlled. 
In the initial phase of orientation and SfM image-matching, where the tie points extraction is computed, a unique photogrammetric block of images is processed for the image position estimation ( $\mathrm{T} 1$, T2, T3, T4, with $\mathrm{n}^{\circ} 252$ images and almost $1 \mathrm{mls}$ of tie points extracted). Here it was possible to test the image-matching performances in case of images differently characterized from a radiometric point of view, due to the significant changes in the scenes. In the subsequent $B B A$ step, only one points set was employed, here the T2 control points were included for block triangulation ( ${ }^{\circ} 18$ GCPs, Figure 8); for T2 triangulation, the metric results the RMSE errors residuals on the CPs are reported in Table 6 .
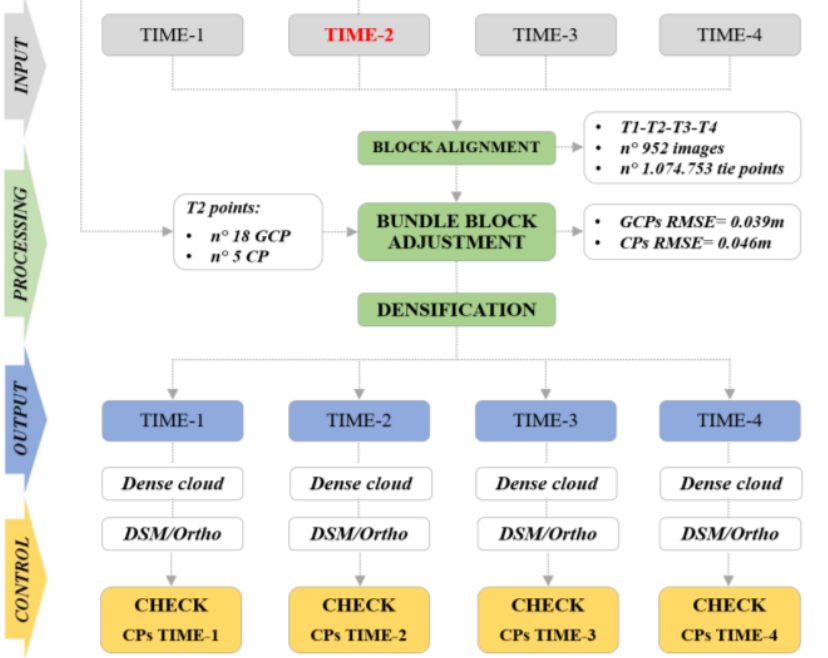

Figure 7. Ad-hoc workflow for multi-temporal co-registration

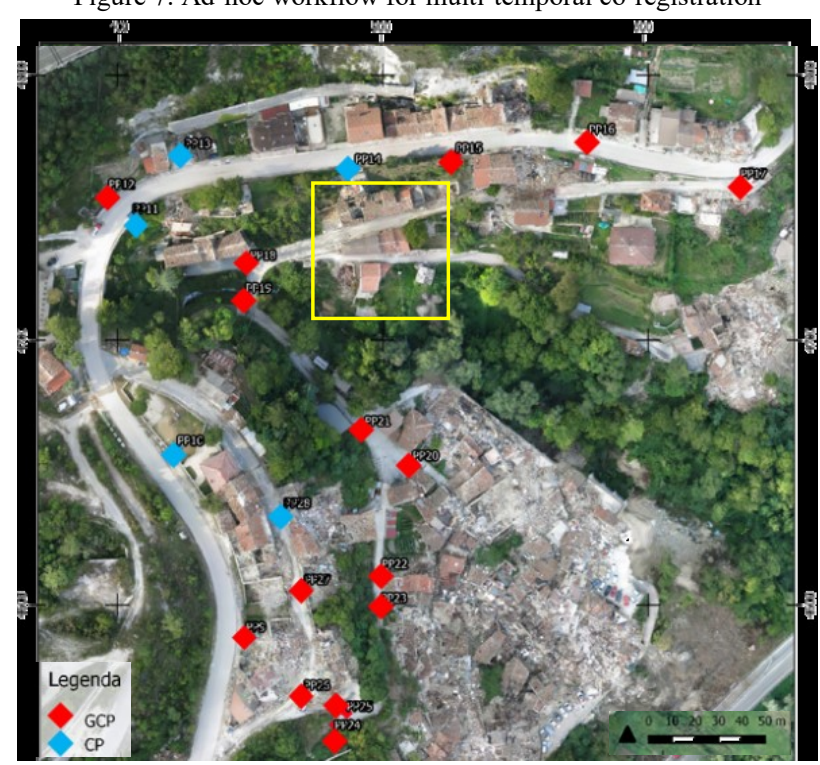

Figure 8. GCPs and CPs distribution superimposed in the T3 ortho

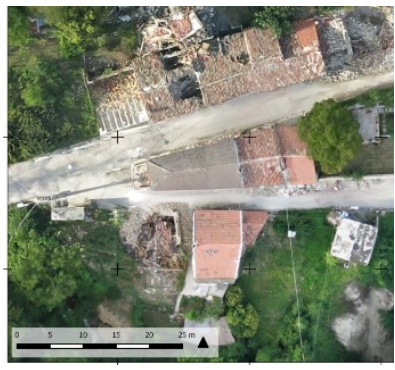

(a)

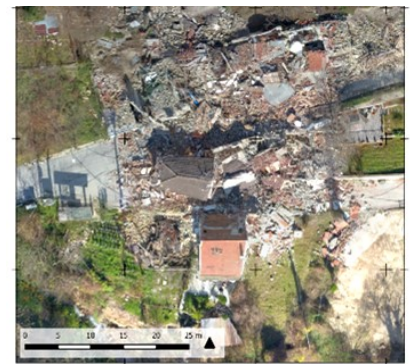

(b)
Figure 9. Comparison between T1-T4 in the northern area of Pescara del Tronto: zoomed excerpt of September (a) and December (b).
After the BBA, with the use of the reference block and GCPs, the densification process is being completed for the whole four datasets, and the DSM and orthoimage computation as well. The metric control is needed and the validation of the geospatial products for T1, T3, T4 (ortho and DSM) is performed with the use of respective CPs wherever possible to be acquired (due to the lack of ground measures in T1, the T3 control measurements are employed). The RMSE results on CPs are reported in Table 7 and demonstrated the processing of metrically controlled 3D models, responding to the detail scale for which they were planned. The December dataset exceeds the acceptability limits due to an intrinsic signal quality problem of GNSS measurement of GCPs.

\begin{tabular}{|l|c|c|c|c|c|}
\hline \multirow{2}{*}{ Dataset } & \multirow{2}{*}{ CPs } & \multicolumn{4}{|c|}{ RMSE (m) } \\
\cline { 3 - 6 } & & X & Y & Z & error \\
\hline T1- August & T3 & 0.039 & 0.044 & 0.264 & 0.116 \\
\hline T3 - October & T3 & 0.028 & 0.039 & 0.243 & 0.010 \\
\hline T4 - December & T4 & 0.079 & 0.283 & 0.511 & 0.291 \\
\hline Table 7. Residual errors about the metric validation on CPS, as in \\
Figure 8.
\end{tabular}

\section{RELIABILITY EVALUATION}

The following paragraph will report the comparatives tests and numerical analyses performed on the UAVs metric products, in order to prove the possibility to integrate high-scale information in the DM procedures, as the Copernicus observations and grading.
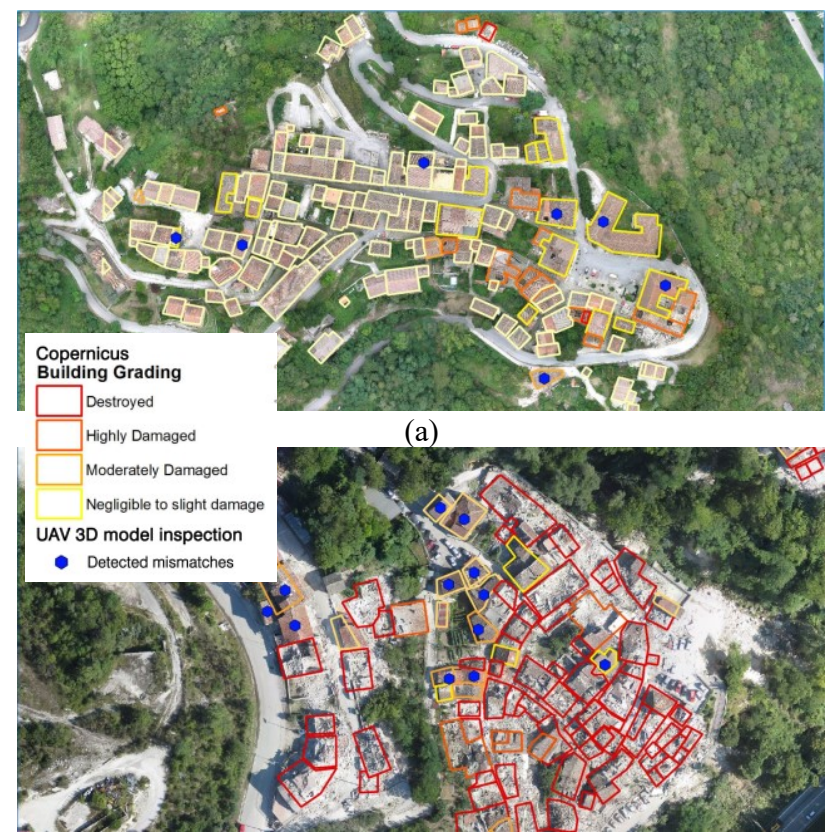

(b)

Figure 10. Excerpt of the UAVs orthophotos of Accumoli (a) and Pescara del Tronto (b) after the seismic event of August. Blue hexagons represent the buildings that need to be reclassified after the analyses performed on the UAVs data.

UAVs have already proved their effectiveness also in the first phases of the response to a disaster, i.e. in the rescue and evacuation of people, and new tools to support these actions are already under development (e.g. software and platforms that allow to remotely monitor several in-flight devices in real-time). However, in this contribution the focus will be on the phases of buildings and infrastructure DA. To simulate a real scenario the different phases of work were dived between two operators: the first one was working in a GIS environment, overlaying the observations of the grading map provided by Copernicus on the 
orthophotos generated from the UAVs data. In the meantime, the second operator was responsible of performing a visual inspection of both the raw data collected by the UAVs and especially of the 3D models generated from them. This simulation was run on the dataset relative to August-September 2016. In the GIS environment all the building of the two test sites were inspected and their classifications, derived from the airborne images used by Copernicus, were integrated with the UAVs data. The results of these analyses are reported in the Discussion, and an overall view of the buildings which classifications need to be adapted to the new assessment is shown in Figure 10 (blue points).

\subsection{Accumoli damage assessment}

A straightforward example of the significant contribute of UAVs for BDA is reported below. In this case one of the main buildings of Accumoli doesn't show almost any roof damages from a nadir point of view and was then classified by the Copernicus EMS as "Negligible to slight damage", Figure 11(a) but the UAVs 3D model contributed to a more accurate analysis in two ways.

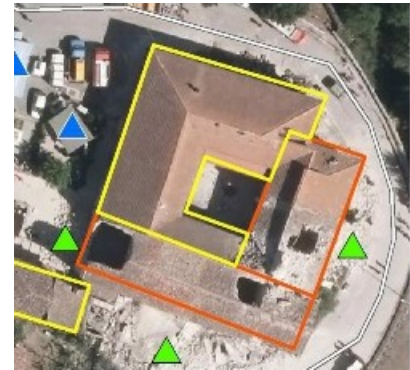

(a)

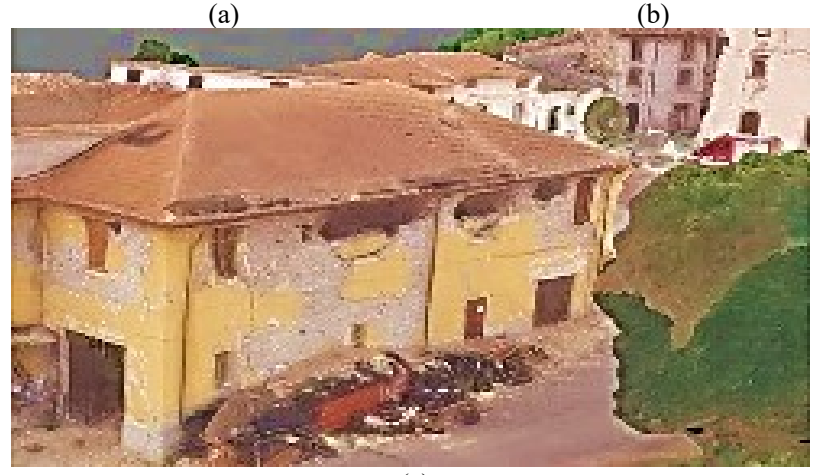

(c)

Figure 11. BDA on Accumoli site, in a sample building. The aerial image of Copernicus (a), the UAVs orthophoto (b) and a view of the considered damaged façade in the 3D model inspection (c).

Firstly, the orthophoto generated after the field survey, with a higher detail, Figure 11(b) allows to identify some debris that were not visible from the airborne image; secondly, the 3D model achieved with the integration of oblique images Figure 11(c) permits to perform an inspection of the façades, revealing some highly damaged portions of the buildings that were otherwise not identifiable. Moreover, a significant contribute of UAVs mapping in Central Italy was related with the Geotechnical reconnaissance. In the report created by the GEER team (GEER, 2016b) it's clearly visible a good example, specifically for the Accumoli site, where a system of cracks in the ground was identified between the UAV photogrammetric mapping of September and December.

\subsection{Pescara del Tronto damage assessment}

In Pescara del Tronto the BDA was a more complex task, compared with the one of Accumoli, due to different factors: the city of Pescara is more extended and topographically complex, and it was subjected to a bigger damage after the first August's earthquake. As clearly reported in the Copernicus grading map, a large portion of the settlement, the east part, suffered high damages and a lot of buildings collapsed or were almost destroyed. This factor, combined with the presence of numerous debris, made the BDA more difficult and subjected to mismatches. An evident example is reported in Figure 12: due to the high number of destroyed surrounding buildings, and consequently to the debris, it was almost impossible to identify with a high level of confidence the damage grading of the considered building, here "Moderately damaged". In this case the contribute of the 3D model derived from the UAVs approach, Figure 12(b) was crucial to identify the high level of damages suffered from the building and to propose a more reliable classification in the BDA phase.

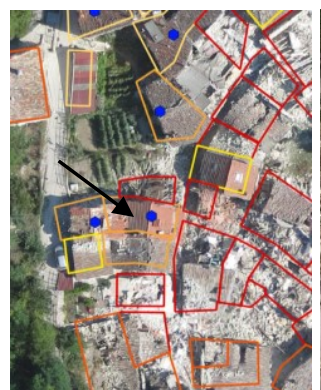

(a)

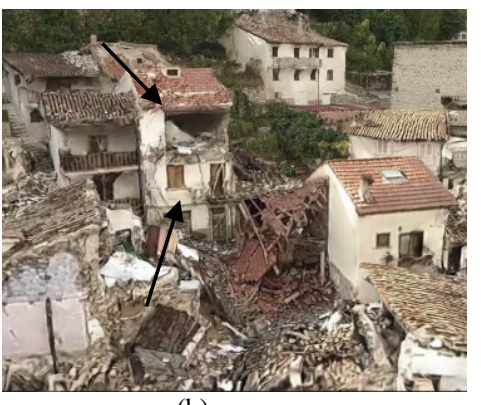

(b)
Figure 12. BDA with UAVs data integration: (a) excerpt of UAV orthophoto in Pescara del Tronto, overlaid with Copernicus grading shapefile, and 3D inspection (b) of UAV DSM (blue points, mismatches). The sample building

(arrow), is considered moderately damaged (right) but it appears

completely damaged by the façades inspection in the 3D model (left).

\section{DISCUSSION}

As previously stated, one of the main aims of the presented research was to analyse and validate some best practices connected to the deployment of UAV devices for photogrammetric purposes and high-scale mapping in the BDA procedures. The first step of the validation was related to propose some standardisable procedures for maximize the informative content of UAV data, through the enhancements of georeferencing strategies, blocks orientation and multitemporal co-registration solutions, within a simplified operative workflow. Each proposed approach has been tested and the spatial products have been metrically controlled in order to evaluate their respondence to the confidence level required by BDA approach. The same 3D models have been integrated in an EMS simulated inspection procedure, in order to assist the damage detection, that is particularly crucial if the façades are considered.

\begin{tabular}{|c|c|c|c|c|c|c|c|}
\hline \multicolumn{2}{|c|}{ BUILDING GRADING } & 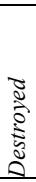 & 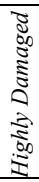 & 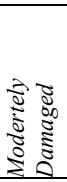 & 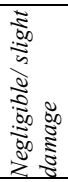 & 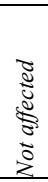 & ำ \\
\hline \multicolumn{2}{|c|}{$\begin{array}{c}\text { Copernicus observation } \\
{\left[\mathrm{n}^{\circ}\right]} \\
\end{array}$} & 2 & 13 & 3 & 15 & 122 & 155 \\
\hline \multirow{4}{*}{ 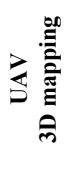 } & Mismatches & 0 & 0 & 1 & 4 & 2 & 7 \\
\hline & underestimated & 0 & 0 & 1 & 4 & 2 & 7 \\
\hline & overestimated & 0 & 0 & 0 & 0 & 0 & $\mathbf{0}$ \\
\hline & Deviation & & & & & & $4.5 \%$ \\
\hline \multirow{2}{*}{\multicolumn{2}{|c|}{$\begin{array}{l}\text { 3D model visual } \\
\text { assessment needed }\end{array}$}} & - & - & 1 & 1 & 0 & 2 \\
\hline & & & & & & & $28.6 \%$ \\
\hline
\end{tabular}

Table 8. Damage detection analysis adjustment for the Accumuli site

Besides, in Table 8 and Table 9 some statistical analyses on the twodatasets considered are reported, in case of discrepancies with EMS grading about the buildings included in each category. In fact, in both the cases, the deviation of damage detection is particularly evident 
when UAVs data (both high-scale orthoimages and 3D navigable models) are used for inspection. In the Accumoli analysis, where the earthquake effects were relatively limited (at least for the August event) only two observations on 7 executed needed the visual assessment from UAV model. Whereas, in the more affected context of Pescara del Tronto, where the statistical population has been more significative, almost half of the mismatches required the observation of the UAV data and thus the 3D information crucial contribute.

\begin{tabular}{|c|c|c|c|c|c|c|c|}
\hline \multicolumn{2}{|c|}{ BUILDING GRADING } & 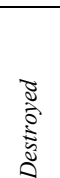 & 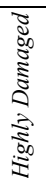 & 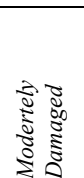 & 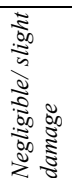 & 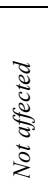 & ș \\
\hline \multicolumn{2}{|c|}{$\begin{array}{c}\begin{array}{c}\text { Copernicus observation } \\
{\left[\mathrm{n}^{\circ}\right]}\end{array} \\
\end{array}$} & 128 & 19 & 16 & 10 & 45 & 218 \\
\hline \multirow{4}{*}{ 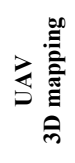 } & Mismatches & 6 & 1 & 7 & 4 & 14 & 32 \\
\hline & underestimated & 0 & 1 & 7 & 4 & 14 & 26 \\
\hline & overestimated & 6 & 0 & 0 & 0 & 0 & 6 \\
\hline & Deviation & & & & & & $14.7 \%$ \\
\hline \multicolumn{2}{|c|}{$\begin{array}{l}\text { 3D model visual } \\
\text { assessment needed }\end{array}$} & 1 & 0 & 3 & 2 & 9 & $\begin{array}{c}15 \\
46.9 \%\end{array}$ \\
\hline
\end{tabular}

Table 9. Damage detection adjustment for the Pescara del Tronto site.

\section{CONCLUSION AND FUTURE PERSPECTIVES}

The emergency response experience after the recent seismic events in Central Italy proven that DM strategies are nowadays oriented towards a multiscale data acquisition approach; satellite products related to the emergency mapping have, in fact, well known strengths, but also inherent weakness that are currently under improvement. Within the aim of further increasing the quality of the acquired images, and the subsequent reliability of the damage assessment procedures, the use of airborne images is currently under investigation and, as shown in this research, the introduction of UAV platform in the DM procedures seems to be the next step forward to increase the resolution of the gathered data. Another issue to take into account is the subjectivity of the operator related to the damage classification procedure, based on the visual interpretation of detectable effects from a nadir view; as presented in the article the use of 3D models generated from UAV nadir and oblique data can mitigate this gap on uncertainty. The experimented semi-automatic approach, based on the integrated interpretation of orthoimagery, DSM and 3D model navigation, shown promising result that support the integration of a high scale UAV image-based approach in the endorsed protocols and operative workflows for the DM in emergency response. It is however important to consider also the limitations of the UAV navigation at a low altitude in relatively dense urban scenarios; ground-based survey inspections, in fact, seem to be still required in those cases where the from-above visual interpretation is doubtfully, for example with the use of rangebased MMSs. In this context, also the emerging low-cost technologies, as $360^{\circ}$ cameras, or the simple use of images acquired by smartphone or tablet, used in ad hoc app, e.g. Mapillary (https://www.mapillary.com) or Open Street Cam (https://www.openstreetcam.org/), could provide benefits that can furtherly be investigated and integrated in the damage assessments operations protocols.

\section{ACKNOWLEDGEMENTS}

Authors would like to thank especially Politecnico di Torino (Prof. Foti S.), for the earthquake task force organization and for kindly providing the technical and financial support for the personne involved in the reconnaissance. We also acknowledge the Team DiRecT (https:/www.facebook.com/ Team-Direct) and, particularly, Prof. Lingua A., Maschio P., Dabove P., Di Pietra V., Grasso, N., Battino A. Thanks to Patrucco G. for helping in the data elaboration. Finally, the authors greatly thank the firefighters RPAS group (Di Lolli A., Lorusso O., Feliziani F. Fiorini M.), which has constantly accompanied us in the fieldwork, assisting with people and resources, and the Italian Department of Civil Protection; thanks to the GEER Association (http:/www.geerassociation.org), with whom we have made a fruitful collaboration.

\section{REFERENCES}

Ajmar, A., Boccardo, P., Disabato, F., \& Giulio Tonolo, F. (2015). Rapid Mapping: geomatics role and research opportunities. Rendiconti Lincei, 26(S1), 63-73. https://doi.org/10.1007/s12210-015-0410-9

Bitelli, G., Camassi, R., Gusella, L., \& Mognol, A. (2004). IMAGE CHANGE DETECTION ON URBAN AREA: THE EARTHQUAKE CASE. International Archives of Photogrammetry and Remote Sensing, 35, 692-697.

Boccardo, P. (2013). New perspectives in emergency mapping. European Journal of Remote Sensing, 46(1), 571-582. https://doi.org/10.5721/EuJRS20134633

Boccardo, P., Chiabrando, F., Dutto, F., Tonolo, F., \& Lingua, A. (2015). UAV Deployment Exercise for Mapping Purposes: Evaluation of Emergency Response Applications. Sensors, 15(7), 15717-15737. https://doi.org/10.3390/s150715717

Boccardo, P., \& Giulio Tonolo, F. (2015). Remote Sensing Role in Emergency Mapping for Disaster Response. In Engineering Geology for Society and Territory - Volume 5 (pp. 17-24). Cham: Springer International Publishing. https://doi.org/10.1007/978-3-319-09048-1_3

Copernicus Emergency Management Service. (n.d.). Retrieved February 15, 2018 from http://emergency.copernicus.eu

Crommelinck, S., Bennett, R., Gerke, M., Nex, F., Yang, M., \& Vosselman, G. (2016). Review of Automatic Feature Extraction from High-Resolution Optical Sensor Data for UAV-Based Cadastral Mapping. Remote Sensing, 8(8), 689. https://doi.org/10.3390/rs8080689

Cusicanqui, J., Kerle, N., \& Nex, F. (2018). Usability of aerial video footage for 3D-scene reconstruction and structural damage assessment, (January), 1-23.

Duarte, D., Nex, F., Kerle, N., \& Vosselman, G. (2017). TOWARDS A MORE EFFICIENT DETECTION OF EARTHQUAKE INDUCED FACCADE DAMAGES USING OBLIQUE UAV IMAGERY. ISPRS - International Archives of the Photogrammetry, Remote Sensing and Spatial Information Sciences, XLII-2/W6, 93-100. https://doi.org/10.5194/isprs-archives-XLII-2-W6-93-2017

Ezequiel, C. A. F., Cua, M., Libatique, N. C., Tangonan, G. L., Alampay, R., Labuguen, R. T., ... Palma, B. (2014). UAV aerial imaging applications for post-disaster assessment, environmental management and infrastructure development. 2014 International Conference on Unmanned Aircraft Systems (ICUAS), (August), 274-283. https://doi.org/10.1109/ICUAS.2014.6842266

Fernandez Galarreta, J., Kerle, N., \& Gerke, M. (2015). UAV-based urban structural damage assessment using object-based image analysis and semantic reasoning. Natural Hazards and Earth System Science, 15(6), 1087-1101. https://doi.org/10.5194/nhess-15-1087-2015

GEER, 2016b. Engineering Reconnaissance of the 24 August 2016 Central Italy Earthquake. Version 2, Zimmaro, P and Stewart, J. P. (editors), Geotechnical Extreme Events Reconnaissance Association Report No. GEER-050B. doi: 10.18118/G61S3Z.

GEER, 2017a. Engineering Reconnaissance following the October 2016 Central Italy Earthquakes - Version 2, Zimmaro, P. and Stewart, J. P. (editors), Geotechnical Extreme Events Reconnaissance Association Report No. GEER-050D. doi: 10.18118/G6HS39

He, M., Zhu, Q., Du, Z., Hu, H., Ding, Y., \& Chen, M. (2016). A 3D Shape Descriptor Based on Contour Clusters for Damaged Roof Detection Using Airborne LiDAR Point Clouds. Remote Sensing, 8(3), 189. https://doi.org/10.3390/rs8030189

Kerle, N. (2010). Satellite-based damage mapping following the 2006 Indonesia earthquake- How accurate was it? International Journal of Applied Earth Observation and Geoinformation, 12(6), 466-476. https://doi.org/10.1016/j.jag.2010.07.004

Lemoine, G., Corbane, C., Louvrier, C., \& Kauffmann, M. (2013). Intercomparison and validation of building damage assessments based on post-Haiti 2010 earthquake imagery using multi-source reference data. Natural Hazards and Earth System Sciences Discussions, I(2), 1445-1486. https://doi.org/10.5194/nhessd-1-1445-2013

Nex, F., Rupnik, E., Toschi, I., \& Remondino, F. (2014). Automated processing of high resolution airborne images for earthquake damage assessment. ISPRS - International Archives of the Photogrammetry, Remote Sensing and Spatial Information Sciences, XL-1(1), 315-321. https://doi.org/10.5194/isprsarchives-XL-1-315-2014

Rastiveis, H., Samadzadegan, F., \& Reinartz, P. (2013). A fuzzy decision making system for building damage map creation using high resolution satellite imagery. Natural Hazards and Earth System Science, 13(2), 455-472. https://doi.org/10.5194/nhess-13-455-2013

Rester, M., Spruyt, P., De Groeve, T., Damme, O. Van, \& Ali, A. (2013). Unmanned Aeria Systems for Rapid Mapping UASRapidMap. Joint Research Centre, TR, Rept. LB-NA-2645I$E N-N$. Joint Research Centre, TR, Rept. LB-NA-26451-EN-N, https://doi.org/10.2788/58375

Vetrivel, A., Gerke, M., Kerle, N., Nex, F., \& Vosselman, G. (2017). Disaster damage detection through synergistic use of deep learning and 3D point cloud features derived from very high resolution oblique aerial images, and multiple-kernel-learning. ISPRS Journal of Photogrammetry and Remote Sensing. https://doi.org/10.1016/j.isprsjprs.2017.03.001

Voigt, S., Schneiderhan, T., Twele, A., Gähler, M., Stein, E., \& Mehl, H. (2011). Rapid Damage Assessment and Situation Mapping: Learning from the 2010 Haiti Earthquake. American Society for Photogrammetry and Remote Sensing., 77(9), 923-931. 